\title{
Advances in the management of enuresis
}

\section{Mesut Tek and Erim Erdem*}

\author{
Address: Department of Urology, Mersin University School of Medicine, Mersin 33079, Turkey \\ * Corresponding author: Erim Erdem (erdemerim@mersin.edu.tr) \\ FI000Prime Reports 2014, 6:106 (doi:10.12703/P6-106) \\ All Fl000Prime Reports articles are distributed under the terms of the Creative Commons Attribution-Non Commercial License \\ (http://creativecommons.org/licenses/by-nc/3.0/legalcode), which permits non-commercial use, distribution, and reproduction in any medium, \\ provided the original work is properly cited. \\ The electronic version of this article is the complete one and can be found at: http://f $1000 . c o m /$ prime/reports $/ \mathrm{m} / 6 / 106$
}

\begin{abstract}
There are still many undiscovered facts about enuresis, even though it is a very old "symptom". It is a significant health problem with a high prevalence among children and a lower prevalence in adulthood. Many treatment guidelines have been proposed for the management of this problem. The improvement of diagnostic tools, and also treatment modalities, have had a significant impact on success rates; however, the long-term success rates need to be higher, especially in resistant cases. In this report, we summarize the advances made in the diagnosis and treatment of enuresis.
\end{abstract}

\section{Introduction}

The prevalence of enuresis is between 15 and $25 \%$ at 5 years of age. Although nocturnal enuresis has a spontaneous resolution rate of $15 \%$ per year, by the age of 15 years it persists in $0.5-1 \%$ of the population, and it may have a deep impact on a child or young person's behavior, emotional well-being and social life. It is also very stressful for the parents/care givers $[1,2]$. The exact definition of enuresis has been revised over the years. The last terminological change was made in 2006 by the International Children's Continence Society (ICCS) report which was updated in 2014, and enuresis is now located under intermittent incontinence. Usage of the term "enuresis" is recommended to define nighttime intermittent incontinence, although "enuresis nocturna" may be used to add extra clarity. However, it has been recommended that usage of the term "diurnal enuresis" should be avoided and "daytime incontinence" should be used $[3,4]$. Since that report there has been a reduction in the usage of "enuresis" without "nocturna", resulting in a consensus on routine usage of the term "enuresis nocturna" (or nocturnal enuresis).

Nocturnal enuresis has undoubtedly occurred since the earliest days of humanity and the first reference may be found in the Ebers papyrus of 1550 BC. In 1472, Paulus Bagellardus of Padua published the first book on diseases of children, including a chapter entitled "On incontinence of urine and bedwetting". In the eighteenth century, enuretic children were subjected to a variety of chemical and mechanical treatments. For example, Dickson in 1762 applied vitriol to the sacral area to raise a blister and provide counter irritation [5]. Despite thousands of years of recognition of the problem, it is clear from the current literature that the etiology is not well understood and that there have been few therapeutic advances. In most cases the "real" etiology is not known and the success rate of therapy not as high as it should be.

The causes of bedwetting are not fully understood. Bedwetting can be considered a symptom that may result from a combination of different factors. There are a number of different disturbances of physiology that may be associated with bedwetting. It is hypothesized that bedwetting is related to genetics, sleep arousal dysfunction, maturational delay, stress, poor toilet training, altered smooth-muscle physiology and, occasionally, organic causes. In the past, enuresis has also been thought to be a psychological problem, but now it is more commonly thought that psychological problems may be the result of enuresis instead of being the cause. In fetal life, bladder contraction is regulated with a reflex arch, which is mediated by sacrospinal ganglia. With age, the centers in pons, medulla and the cerebral cortex take up their roles and suppress this reflex arch, and bladder capacity also increases. In order to achieve nighttime continence, the 
maturation of different systems (such as abolition of spontaneous bladder contractions, circadian secretion of antidiuretic hormone [ADH] for regulating nighttime urine volume and attainment of sleep arousal) need to act together in synergy. Delay in this maturational process may result in enuresis.

Many urodynamic studies have shown that bladder function falls within the normal range in most children with nocturnal enuresis. Unstable contractions are found in up to half of sleep cystometric studies, but these contractions do not necessarily lead to incontinence [6].

The fact that bedwetting occurs while sleeping suggests the hypothesis that enuretics have a sleep disturbance that allows them to sleep too deeply. Although there are conflicting data, a summary of nighttime encephalography, monitoring of eye movements and urodynamic findings suggest that the sleep patterns of enuretics are not different from those of the normal population. Instead, enuresis is related to a delay in central nervous system (CNS) development or, more accurately, dual delay in the development of the perception and inhibition of bladder filling and contraction by the CNS [7].

About $50 \%$ less urine is normally excreted during the night than during the day. A circadian rhythm of plasma arginine vasopressin, which normally increases at night, is responsible for this fact [8]. Many children with nocturnal enuresis have similar levels of arginine vasopressin during both day and night, which might cause the development of nocturnal polyuria. This nocturnal polyuria is thought to overwhelm the bladder's ability to retain urine until morning $[9,10]$.

As described above, nighttime detrusor overactivity, lack of arousal from sleep/maturational deficit of the brainstem, and increased nocturnal urine output have all been shown to play a part in enuresis. Some experts, like Yeung et al., combined these causes, suggesting they were parts of a single pathophysiological process [11]. Yeung et al. proposed that severe enuretics have a smaller capacity bladder with unstable nighttime contractions combined with an abnormal brain-bladder dialogue that causes light sleep, with frequent cortical arousals, but an inability to awaken. In summary, however, in most cases there is no specific known etiology, and therefore we define enuresis as a "symptom" that may have many causes.

\section{Work-up and Confirmation of Diagnosis}

In the last four years, guidelines for the management of enuresis have gained popularity as a means of standardizing care. In all, the diagnostic approach can be summarized as making certain that the enuresis is "monosymptomatic": ruling out significant anatomic and neurologic causes, as well as separating out those patients with daytime symptoms.

A carefully obtained history, a thorough physical examination and urinalysis are sufficient for most children who present with bedwetting. The aim of this evaluation is to identify those children who require further investigation. Parents should be questioned about their family history and the child's medical history. Careful questioning of parents and children can be extremely helpful in determining the type of enuresis and a possible cause or contributing factors.

Children with enuresis usually have normal results upon physical examination. However, in cases of enuresis the physician needs to check the flanks and abdomen for masses, including an enlarged bladder. The lower back should be inspected for cutaneous lesions, dimples or any variant of spina bifida. Often an anal wink can be elicited, which suggests that local spinal cord reflexes are intact.

Urinalysis is performed to assess specific gravity (can the child concentrate their urine?) and urinary glucose level (to rule out diabetes mellitus), in addition to blood/ protein analysis (signs of nephrologic abnormalities), and to rule out urinary tract infection. If the history, physical examination and urinalysis are negative, no further investigations (such as radiographic studies or cystoscopy) are needed.

The authors of the consensus paper on guidelines for the management of enuresis proposed a two-step approach [9]. Assuming the basic work-up is normal, they recommended treating constipation, regulating eating and drinking habits, and reassuring children and families that this is common and that there is no serious medical problem. These are all components of the initial treatment strategy, which was defined as "urotherapy" by the ICCS [4]. In addition, it should be emphasized that most children will spontaneously resolve at a rate of $15 \%$ per year, even with no treatment. Regarding constipation, it has been well accepted that this occurs concomitantly with monosymptomatic nocturnal enuresis. The ICCS paper reports that many physicians and parents have used different definitions of constipation and, to solve this issue, the authors recommend usage of Rome III criteria for diagnosis. Although, there are no clear data showing that the treatment of constipation helps nocturnal enuresis, in our opinion constipation should be diagnosed and treated when possible [12].

If this first step is unsuccessful and the family is motivated to do more, the clinician should proceed to the second 
step. This would include a detailed daytime and nighttime urinary diary. This helps to be more certain that the patient has truly monosymptomatic nocturnal enuresis (with no daytime issues) and also provides more data about bladder capacity and nighttime urine volume.

After the above work-up and confirmation of the diagnosis of monosymptomatic enuresis, more aggressive treatment can be considered. Some families will be happy that there is no serious medical issue and that there is a high spontaneous resolution rate. If, however, families do wish to proceed with treatment, there are two effective alternatives, which have level 1 , grade A recommendations in guidelines.

\section{Treatment}

\section{Bedwetting alarm}

Although the exact mechanism of alarm therapy is not well understood, one of the possible mechanisms has been explained by classic conditioning theory. The child is woken by the bell in order to get up and complete voiding into the toilet. A more appropriate approach is an operant type of behavioral technique in which the child learns to suppress his/her bladder emptying during sleep [13]. Alarm therapy is associated with a significant increase in nocturnal bladder capacity in those children who become dry. It is has a response rate of $60 \%$ and the long-term success rate was reported as $43 \%$. The Cochrane review by Glazener et al. [14] reported that nearly half of the children who persisted with a bedwetting alarm remained dry after treatment finished, compared to almost none remaining dry if no treatment was given. Although desmopressin may have a more immediate effect, alarms appear more effective in the long run and the evidence for supplementing alarm treatment with desmopressin was conflicting. Results using alarms were also better than those when using tricyclics, both during and after treatment.

Disruption of sleep for both parents and the child and the relatively long duration for obtaining the result of the treatment are common causes of discontinuation.

\section{Desmopressin}

Desmopressin is a synthetic analog of arginine vasopressin, which reduces urine output. We believe that desmopressin treats nocturnal enuresis by decreasing urine volume at night. Desmopressin has been available as an intranasal spray and in tablet formulations for the treatment of primary nocturnal enuresis for many years; a convenient, sublingual oral desmopressin lyophilisate (MELT) formulation is a more recent development $[15,16]$. Success rates and making the decision to switch from tablet to MELT formula were compared. Juul et al. reported that the probability of being a responder to desmopressin therapy, along with compliance, was higher in those who used the MELT formula [17]. It is a well-tolerated drug with some uncommon side effects such as headache and emotional disturbances, and a very rare possible side effect of water intoxication [13].

In the Cochrane review, it was reported that desmopressin was effective in reducing bedwetting compared with placebo but that no difference persisted after treatment was finished [18]. Recent papers also reported that desmopressin therapy has a response rate of $70 \%$ during the treatment period. Discontinuation of therapy causes a high relapse rate, which can reach $60 \%[3,13]$. There are two factors responsible for this high relapse rate. The first one is "the definition of success". In order to interpret the results, initial response is defined as a $50 \%$ decrease in wet nights, partial response is a $50-99 \%$ reduction in wet nights, and full response is $100 \%$ reduction [4]. In our opinion, success should be defined as "complete dryness". The other factor is the withdrawal method for desmopressin; although it has been in widespread use for years, the best withdrawal method is still not clear. Ferrara et al. compared two withdrawal methods: abrupt withdrawal and structured withdrawal $(60 \mu \mathrm{g} / \mathrm{day}$ for 15 days, and then $60 \mu$ g every second evening for another 15 days). They did not find a difference in relapse rate between the groups [19]. These results were not supported by the study of Haciyev and colleagues who compared relapse rates in four groups of enuretics, in which two different structured withdrawal strategies were compared to placebo and sudden withdrawal. The reported relapse rates after structured withdrawal with MELT formulation were lower. They also found that high initial dose, and a higher number of wet nights before treatment was initiated, was associated with higher relapse rates [20]. In our opinion, sudden withdrawal of the drug does not correct the disorder but just corrects the inappropriate rhythm of arginine vasopressin secretion.

\section{Treatment modalities}

The most important step in management is choosing between these modalities. We derived Table 1 from the recent consensus paper and suggest that it be used as a guide to simplify this decision making step [9]. On the other hand, a significant number of children will be therapy resistant, even though the appropriate modality was chosen, and the management of these children may be very difficult. The full response rate to alarm therapy is $65 \%$ and the cure rate is $43 \%$, and $31 \%$ and $22 \%$ respectively with desmopressin therapy [2]. The first option for this therapy-resistant group of children is a combination of alarm and desmopressin therapies. However, about $30 \%$ of children also do not respond to combination therapy. 
Table I. Therapy choices for children with enuresis [9]

\begin{tabular}{llll}
\hline Scenario & Bladder Capacity & Nocturnal Urine Volume & Therapy \\
\hline 1 & Normal & Normal & Alarm Therapy or Desmopressin \\
2 & Small & Normal & Alarm Therapy \\
3 & Normal & High & Desmopressin \\
4 & Small & High & Alarm and Desmopressin \\
& & & Combination \\
\hline
\end{tabular}

The possible pathology and treatment modalities can be summarized as follows:

(a) The child may have small bladder capacity. In this case, oxybynin might be the drug of choice. Drug combinations were reviewed in a 2012 Cochrane paper by Deshpande et al. They found that, for drugs versus behavioral therapy, bedwetting alarms were found to be better than oxybutynin, and also better than oxybutynin plus holding exercises, in reducing the number of children failing to achieve 14 consecutive dry nights [21]. However, a combination of desmopressin plus an antimuscarinic drug may be a more effective alternative to desmopressin monotherapy. This combination therapy was also found to be successful as a first-line therapy in a study by Park et al. [22] and, although this is promising, we keenly await independent confirmation.

(b) Some of these children may also have daytime incontinence, which was not discovered initially. A strict voiding regimen should be added to desmopressin plus alarm combination therapy for these children [2].

(c) Some of the non-responders may have absorptive hypercalciuria and may become desmopressinresponders after using a low-calcium diet [2].

\section{Psychological effects}

The psychological effects of nocturnal enuresis are significant. There are relatively few studies that focus upon the psychological impact and health-related quality of life of children who experience bedwetting. In addition, studies of effectiveness have focused on the achievement of dryness as the primary outcome, rather than how treatment might affect social and psychological aspects as well as the quality of life of children and young people and their families. However, in this regard, there have been several studies. Caldwell et al. reported that the children's lower self esteem scores increased after successful treatment, and only $14 \%$ of the children were happy and did not want therapy for enuresis [13]. In a different study, Cederblad et al. explored the everyday dilemmas of the parents of enuretics and identified two main patterns of coping: unworried "wet-bed-fixers" and anxious "night launderers". The latter group cannot talk about enuresis publicly, thereby avoiding the thought that their child has psychological problems. The parents also wondered about the limiting effect of enuresis in their child's present and future life [23]. In another study, Kanaheswari et al. found that enuretics have lower body self-esteem scores, which impair their social relationships. Lower scores correlated with severity of enuresis, more advanced age and female gender [24]. Some studies have shown that self-esteem improves with improvement in the enuresis, but some children and parents may benefit from psychological support. However, it should be remembered that the main reason for treating enuretics is to avoid the negative impact of enuresis on social life and psychological status $[3,13,25]$.

\section{Adult Consequences}

The goal of enuresis therapy can be defined as "avoiding bedwetting". However, a significant number of the children who were "cured" may suffer from nocturia in their adult life. In a German study, bedwetting in children was shown to be associated with nocturia in later life $(P=0.0747$; odds ratio $1: 351)$ [26]. In another study, nocturia was found to have a disruptive effect, reducing productivity by almost $25 \%$ in the working population [27]. Similarly, D'Ancona et al. reported that adults with incontinence were more likely to have a history of childhood enuresis [28]. Thus, although we may be successful in treating the symptom of nocturnal enuresis in these children, there may well be long-term sequelae of the disorder that we are not fully aware of.

\section{Conclusion}

Nocturnal enuresis is a complex problem and the best way to treat it is to determine the exact etiology. In most instances this is not possible. Hence, success is generally focused on reducing the number of wet nights. Whatever the success of the therapy, the psychological aspects of the condition should be considered. Finally, data are just emerging on the adult consequences of the condition and this will be an area of great interest in the future. 


\section{Abbreviations}

CNS, central nervous system; MELT, oral desmopressin lyophilisate; ICCS, International Children's Continence Society.

\section{Disclosures}

The authors declare that they have no disclosures.

\section{References}

I. Guidelines on Paediatric Urology. European Association of Urology (EAU);2010. [http://www.uroweb.org/gls/pdf/Paediatric\% 20Urology\%2020 I0.pdf]

2. Diagnosis and Management of Urinary Incontinence in Childhood. Tekgul S, Nijman R. JM, Hoebeke P, Canning D, Bower W, Von Gontard A. [http://www.ics.org/Publications/ICl_4/files-book/ Comite-9.pdf]

3. Nevéus T, Gontard A von, Hoebeke P, Hjälmås K, Bauer S, Bower W, Jørgensen TM, Rittig S, Walle JV, Yeung C, Djurhuus JC: The standardization of terminology of lower urinary tract function in children and adolescents: report from the Standardisation Committee of the International Children's Continence Society. J Urol 2006, 176:3|4-24.

4. Austin PF, Bauer SB, Bower W, Chase J, Franco I, Hoebeke P, Rittig S, Walle JV, Gontard A von, Wright A, Yang SS, Nevéus T: The Standardization of Terminology of Lower Urinary Tract Function in Children and Adolescents: Update Report from the Standardization Committee of the International Children's Continence Society. J Urol 2014, 191:1863-5.

\section{FlOOOPrime}

\section{RECOMMENDED}

5. Salmon MA: An historical account of nocturnal enuresis and its treatment. Proc R Soc Med 1975, 68:443-5.

6. $\mathrm{Wu} \mathrm{HHH}$, Chen $\mathrm{MT}$, Lee $\mathrm{YH}$ : Urodynamic studies and primary nocturnal enuresis. Chin Med J 1988, 41:227-32.

7. Koff SA: Why is desmopressin sometimes ineffective at curing bedwetting? Scand J Urol Nephrol Suppl 1995, 173:103-8.

8. Nørgaard JP, Djurhuus JC, Watanabe H, Stenberg A, Lettgen B: Experience and current status of research into the pathophysiology of nocturnal enuresis. Br J Urol 1997, 79:825-35.

9. Vande Walle J, Rittig S, Bauer S, Eggert P, Marschall-Kehrel D, Tekgul S: Practical consensus guidelines for the management of enuresis. Eur J Pediatr 2012, 171:971-83.

\section{FlOOOPrime RECOMMENDED}

10. Nørgaard JP, Rittig S, Djurhuus JC: Nocturnal enuresis: an approach to treatment based on pathogenesis. J Pediatr 1989, I 1 4:705-10.

II. Yeung CK, Diao M, Sreedhar B: Cortical arousal in children with severe enuresis. $N$ Engl J Med 2008, 358:24I4-5.

\section{FlOOOPrime}

12. Burgers RE, Mugie SM, Chase J, Cooper CS, Gontard A von, Rittig CS, Homsy Y, Bauer SB, Benninga MA: Management of functional constipation in children with lower urinary tract symptoms: report from the Standardization Committee of the International Children's Continence Society. J Urol 2013, 190:29-36.

13. Caldwell, Patrina HY, Deshpande AV, Gontard A von: Management of nocturnal enuresis. BMJ 20I3, 347:f6259.

14. Glazener, CMA, Evans, JHC, Peto RE: Alarm interventions for nocturnal enuresis in children. Cochrane Database Syst Rev 2005: CD0029II.
15. Abrams P, Cardozo L, Wein A: 3rd International Consultation on Incontinence-Research Society 20II. Neurourol Urodyn 20I2, 31:29I-2.

16. Lottmann H, Froeling F, Alloussi S, El-Radhi AS, Rittig S, Riis A, Persson B: A randomised comparison of oral desmopressin lyophilisate (MELT) and tablet formulations in children and adolescents with primary nocturnal enuresis. Int J Clin Pract 2007, 61:1454-60.

FlOOOPrime RECOMMENDED

17. Juul KV, van Herzeele C, Bruyne P de, Goble S, Walle JV, Nørgaard JP: Desmopressin melt improves response and compliance compared with tablet in treatment of primary monosymptomatic nocturnal enuresis. Eur J Pediatr 2013, 172:1235-42.

18. Glazener CM, Evans JH: Desmopressin for nocturnal enuresis in children. Cochrane Database Syst Rev 2002:CD002II2.

19. Ferrara P, Romano V, Cortina I, lanniello F, Fabrizio GC, Chiaretti A: Oral desmopressin lyophilisate (MELT) for monosymptomatic enuresis: structured versus abrupt withdrawal. J Pediatr Urol 2014, 10:52-5.

20. Gökçe Mi, Hajıyev P, Süer E, Kibar Y, Sılay MS, Gürocak S, Doğan HS, Irkılata HC, Oktar T, Onal B, Erdem E, Aygün YC, Balcı C, Arslan AR, Kaya C, Soygür T, Sarıkaya S, Tekgül S, Burgu B: Does structured withdrawal of desmopressin improve relapse rates in patients with monosymptomatic enuresis? J Urol 2014, 192:530-4.

21. Deshpande AV, Caldwell, Patrina HY, Sureshkumar P: Drugs for nocturnal enuresis in children (other than desmopressin and tricyclics). Cochrane Database Syst Rev 2012, I2:CD002238.

\section{FlOOOPrime}

22. Park SJ, Park JM, Pai KS, Ha TS, Lee SD, Baek M: Desmopressin alone versus desmopressin and an anticholinergic in the firstline treatment of primary monosymptomatic nocturnal enuresis: a multicenter study. Pediatr Nephrol 2014, 29: I 195-200.

\section{FlOOOPrime}

\section{RECOMMENDED}

23. Cederblad M, Nevéus T, Åhman A, Österlund Efraimsson E, Sarkadi A: “Nobody asked us if we needed help": Swedish parents experiences of enuresis. J Pediatr Urol 20I4, 10:74-9.

\section{FlOOOPrime}

24. Kanaheswari Y, Poulsaeman V, Chandran V: Self-esteem in 6- to I6year-olds with monosymptomatic nocturnal enuresis. J Paediatr Child Health 20I2, 48:EI78-82.

\section{FlOOOPrime \\ RECOMMENDED}

25. Robson WLH: Enuresis treatment and management. [http:// emedicine.medscape.com/article/I0I4762-treatment]

26. Goessaert A, Schoenaers B, Opdenakker O, Hoebeke P, Everaert K, Walle JV: Long-Term Followup of Children with Nocturnal Enuresis: Increased Frequency of Nocturia in Adulthood. J Urol 2014, 191:|866-7|.

\section{FIOOOPrime}

27. Andersson F, Blemings A, Holm-Larsen T, Nørgaard JP: Nocturia has a strong impact on productivity - a comparison with different chronic diseases [abstract]. Presented at European Association of Urology poster session Nocturia, OAB, metabolic syndrome - towards a new management': 17 March 2013; Milan, Italy.

28. D'Ancona Carlos Arturo Levi, Lopes, Maria Helena Baena de Moraes, Faleiros-Martins AC, Lúcio AC, Campos RM, Costa JV: Childhood enuresis is a risk factor for bladder dysfunction in adult life? Neurourol Urodyn 2012, 31:634-6.

FlOOOPrime RECOMMENDED 